\title{
Model Induktif Kata Bergambar Sebagai Upaya Meningkatkan Kemampuan Verbal Siswa
}

\author{
${ }^{1}$ Ridwan Budi Pramono, ${ }^{2}$ Rr. Dwi Astuti ${ }^{3}$ Jayanti Putri Purwaningrum \\ ${ }^{1}$ Psikologi, Universitas Muria Kudus, \\ ${ }^{2}$ Psikologi, Universitas Muria Kudus, \\ ${ }^{3}$ Pendidikan Matematika, Universitas Muria Kudus \\ email.1.ridwan.budi@umk.ac.id
}

\begin{abstract}
Abstrack: Kemampuan verbal memegang peranan penting dalam perkembangan kognitif dan akademis anak. Kemampuan verbal juga mendukung pemahaman anak dalam menguasai mata pelajaran yang berimbas langsung pada kemampuan akademisnya. Model induktif kata bergambar merupakan salah satu metode pembelajaran yang fokus pada penguasaan dan pengembangan kosakata. Penelitian ini bertujuan untuk mengetahui efektivitas model induktif kata bergambar dalam meningkatkan kemampuan verbal. Penelitian ini merupakan penelitian kuasi eksperimen dengan desain mengunakan dua kelompok yang diamati. Subjek penelitian adalah siswa kelas 3 sekolah dasar di Kabupaten Kudus yang dibagi menjadi dua kelompok yaitu kelompok kontrol dan kelompok eksperimen. Pengambilan subjek didasarkan pada observasi dan wawancara dengan kriteria yang telah ditetapkan oleh peneliti. Pengukuran dilakukan saat pretes dan posttes menggunakan alat tes WISC. Tes WISC merupakan tes inteligensi yang biasa digunakan untuk mengukur taraf kecerdasan anak usia 5 tahun hingga 15 tahun. Pemberian perlakuan dalam penelitian ini menggunakan metode pembelajaran model induktif kata bergambar. Analisis statistik yang digunakan dalam penelitian menggunakan analisis uji Wilcoxon. Hasil penelitian menunjukkan bahwa ada perbedaan yang signifikan antara sebelum dan sesudah perlakuan dengan skor 0,49 yang termasuk pada kategori sedang dengan sumbangan efektif sebesar 27,58\%.
\end{abstract}

Kata kunci: kemampuan verbal, model induktif kata bergambar, WISC

Abstract: Verbal ability play important roles in children's cognitive and academic development. Verbal ability supports the understanding of children in mastering subjects that directly impact their academic abilities. The picture-word inductive model is a learning method that focuses on mastery and vocabulary development. This study aims to determine the effectiveness of the picture-word inductive model in improving verbal comprehension. This research is a quasi-experimental study with a design using two observed groups. The research subjects were third grade elementary school students in Kudus Regency with control and experimental group. Subject taking was based on observations and interviews with the criteria set by the researcher. Measurements were made at pretest and posttest using the WISC test. The WISC test is an intelligence test commonly used to measure the level of intelligence of children aged 5 years to 15 years. The treatment in this study used picture-word inductive model learning method. Statistical analysis used in the study using Wilcoxon test analysis. The results showed that there were significant differences between before and after treatment with a score of 0,49 which was included in the medium category with an effective contribution of $27.58 \%$.

Keyword: verbal comprehensions, pictorial word inductive model, WISC 


\section{PENDAHULUAN}

Undang-undang No. 20 Tahun 2003 tentang sistem Pendidikan nasional menyiratkan bahwa pendidikan merupakan usaha yang direncanakan untuk menciptakan suasana belajar dan proses belajar aktif bagi peserta didik agar dapat mengembangkan potensi dirinya. Pendidikan formal di Indonesia dimulai dari jenjang pendidikan sekolah dasar. Pendidikan sekolah dasar merupakan pondasi awal, dengan kata lain pendidikan dasar memegang peranan penting bagi keberlangsungan proses pendidikan selanjutnya. Pencapaian akademis yang baik oleh siswa di jenjang pendidikan sekolah dasar memberikan pijakan yang bagus bagi siswa dalam kapabilitasnya mengikuti proses pendidikan di jenjang yang lebih tinggi.

Inteligensi yang merupakan variabel kognitif masih merupakan prediktor yang relevan bagi pencapaian akademis (Deary, Strand, Smith, \& Fernandes, 2007; Jensen, 1998; Kuncel, Hezlett, \& Ones, 2004; Schneider, Lotz, \& Sparfeldt, 2018). Hubungan antara inteligensi dan prestasi akademik merupakan salah satu korelasi yang signifikan ketika membahas kemampuan kognitif. Banyak studi penelitian menunjukkan hubungan sedang sampai kuat antara skor inteligensi dan prestasi sekolah. Inteligensi dapat didefinisikan sebagai kemampuan intelektual, seseorang yang memecahkan teka-teki silang dengan cepat atau memberikan jawaban yang benar tentang soal matematika yang rumit atau mendapatkan skor inteligensi yang tinggi dapat diartikan bahwa orang tersebut menunjukkan perilaku yang cerdas dan dapat dikatakan orang tersebut cerdas, namun seseorang yang buruk dalam mengerjakan tugas-tugas seperti tadi, dapat diartikan orang tersebut tidak menunjukkan perilaku yang cerdas dan mungkin mempunyai tingkat kecerdasan yang rendah (Dodonova \& Dodonov, 2012). Hal ini mungkin terjadi karena beberapa hal. Rendahnya performa, bahkan saat dilakukan tes inteligensi, mungkin karena kelelahan, kurangnya minat atau motivasi, munculnya kecemasan atau penyebab lainnya (Colman, 1990). Kajian meta analisis tentang hubungan inteligensi dan prestasi siswa sekolah dasar menunjukkan bahwa semakin tinggi inteligensi semakin baik raport siswa (Roth et al., 2015). Bahkan jika siswa kurang berusaha dalam menyelesaikan tugas-tugas sekolah menyebabkan prestasi akademis yang mereka capai tidak mencerminkan kapasitas mereka untuk menjadi siswa yang sukses secara akademis (Spinath \& Spinath, 2005).

Kapabilitas untuk dapat berkomunikasi merupakan hal yang sangat penting bagi pencapaian akademis dan kesuksesan karir (Morreale \& Pearson, 2008). Pada lingkup sekolah dan pekerjaan, seseorang yang pandai berbicara cenderung lebih berhasil dalam menyampaikan pengetahuan, ide dan opini mereka, serta mampu berkomunikasi untuk membangun hubungan dengan teman, orang tua dan guru (Herbein et al., 2018; Hunt, Wright, \& Simonds, 2014; Morreale \& Pearson, 2008). Semua sistem komunikasi, baik yang sederhana maupun rumit, mempunyai prinsip yang sama, yaitu mengantarkan sinyal pesan dari sumber ke tujuan. Bahasa adalah satu-satunya symbol yang digunakan oleh manusia untuk berkomunikasi (Krauss, 2002).

Kemampuan verbal memegang peranan penting bagi perkembangan anak secara akademis dan verbal. Pemahaman konsep, bacaan membutuhkan peran dari kemampuan verbal, karena konsep terdiri dari situasi, kejadian, kata-kata dan bagian bagian yang diklasifikasikan menjadi kategori (Piacente, 2012). Kompetensi yang harus dikuasai agar proses pembelajaran berjalan dengan baik salah satunya adalah pemahaman bacaan yang menekankan pentingnya kosakata dan pengetahuan yang sudah dikuasai sebelumnya ketika seseorang berinteraksi dengan teks tertulis. Anak yang mengalami permasalahan dengan bahasa kemungkinan besar mengalami permasalahan dengan atensi dan perhatiannya, kedua hal tersebut berperan penting bagi anak untuk memahami instruksi. Selain itu, pemahaman, mengingat kembali yang dibaca, konsep waktu terkadang juga menjadi permasalahan dan membingungkan bagi anak serta yang krusial adalah bagaimana mereka kesulitan untuk menyusun kalimat bertanya yang tepat ketika mereka membutuhkan bantuan (Piacente, 2012).

Beberapa penelitian menekankan pentingnya kemampuan verbal pada anak-anak. Kecerdasan verbal terbukti merupakan hal yang berpengaruh secara signifikan pada strategi seleksi dan aplikasi anak serta kemampuan verbal memberikan efek langsung pada keahlian membaca dan menulis yang berguna dalam pencapaian matematika (Caemmerer, Maddocks, Keith, \& Reynolds, 2018; Luwel, Foustana, Onghena, \& Verschaffel, 2013). Penelitian tentang peningkatan kemampuan berbicara 
siswa sekolah dasar di depan umum, menekankan pentingnya penguasaan topik mata pelajaran dan kemampuan verbal siswa sebelum mereka belajar untuk berpidato (Herbein et al., 2018)

Ada banyak instrument dan prosedur untuk mengukur kemampuan verbal salah satunya adalah skala Wechsler. Skala Wechsler merupakan alat ukur inteligensi yang telah diterjemahkan, diadaptasi dan distandardisasi di puluhan negara di seluruh dunia. Seri tes Wechlser terdiri dari Wechsler Intelligence Scale for Children (WISC), Wechsler Preschool and Primary Scale of Intelligency (WPPSI) dan Wechsler Adult Intelligence Scale (WAIS) yang tiap tes ini telah mengalami revisi selama beberapa dekade (Weiss, Saklofske, Holdnack, \& Prifitera, 2016). Skala-skala inteligensi Wechsler merupakan salah satu yang terbaik di antara karena mempunyai data psikometrik yang baik dan menghasilkan informasi yang relevan bagi praktisi (Gary, 2003). WISC merupakan adaptasi Wechsler-Bellevue Intelligence Scale dan didesain dengan sub-tes baru yakni verbal comprehension dan performance.

Pengajaran dan pembelajaran formal tentang literasi dan kompetensi matematika dimulai saat siswa memasuki sekolah dasar. Penguasaan kemampuan verbal dan angka sejak dini mampu mendukung perkembangan kompetensi siswa saat menjalani proses pembelajaran, dan keberhasilan siswa setelah lulus dari sekolah (Duncan et al., 2007; Geary, 2011). Guru berperan penting dalam meningkatkan ketrampilan baca-tulis siswa, guru yang menyediakan akses dan pilihan pada mereka. Semakin banyak kosakata yang diketahui siswa, semakin banyak pemahaman yang mereka miliki tentang dunia di sekitar mereka (Huda, 2014).

Model pembelajaran induktif kata bergambar fokus pada pengembangan kosa kata, bagaimana menyimpan dan memindah kata-kata tersebut ke dalam memori jangka panjang (Joyce, Weil, \& Calhoun, 2011). Pendekatan model ini menitikberatkan pada kemampuan kosakata siswa. Siswa membaca dengan cara mengeja kosakata tertentu yang terdapat pada gambar, kemudian menulisnya kembali. Latihan ini bertujuan agar siswa dapat membaca dan mengembangkan kosakata yang mereka kuasai dan diharapkan dapat memahami berbagai teks lainnya. Penggunaan gambar sebagai stimulus merupakan konsep awal dalam model ini, untuk menambah pengalaman berbahasa dalam pembelajaran di kelas. Model induktif kata bergambar adalah salah satu strategi pembelajaran yang menarik sehingga diharapkan siswa dapat meningkatkan kosakatanya (Kusminah, 2012). Model ini juga memberikan keluasaan bagi guru untuk menyampaikan materi dan menerapkannya. Model induktif kata bergambar adalah salah satu kelompok model pembelajaran yang bertujuan untuk memproses informasi sebab fokus pedagogiknya terletak pada strukturasi materi pelajaran sehingga siswa dapat meneliti bahasa, bentuk dan penggunaannya seperti bagaimana huruf, kata, frasa, kalimat atau teks yang lebih panjang dapat digunakan untuk mendukung proses komunikasi (Huda, 2014). Model induktif kata bergambar membentuk kemampuan siswa dengan cara (1) belajar membuat kosakata; (2) belajar meneliti struktur kata dan kalimat; (3) menghasilkan tulisan (judul, kalimat dan paragraph); (4) menghasilkan pemahaman tentang hubungan membaca/menulis; (5) mengembangkan ketrampilan analisis fonetik dan structural; (6) mengembangkan minat dan kemampuan untuk berekspresi dengan tulisan; (7) meningkatkan gairah membaca teks-teks nonfiksi; dan (8) mengembangkan ketrampilan kerja sama dalam belajar bersama orang lain dalam ranah membaca/menulis (Huda, 2014).

Penelitian ini bertujuan untuk menganalisis efektivitas model induktif kata bergambar dalam meningkatkan kemampuan verbal siswa Sekolah Dasar (SD). Pemberian metode pembelajaran model induktif kata bergambar diharapkan meningkatkan kemampuan verbal siswa sehingga mereka mampu menjalani proses pendidikan dengan kemampuan verbal yang lebih baik untuk mencapai prestasi akademik yang memuaskan.

\section{METODE}

Penelitian ini menggunakan tes WISC dengan subtes Verbal Comprehension untuk melakukan tes kemampuan verbal. Penelitian ini menguji efektivitas model induktif kata bergambar dalam meningkatkan kemampuan verbal siswa. Subjek dalam penelitian ini menggunakan teknik purposive sampling dimana subjek mempunyai kualitas dan karakteristik tertentu yang ditetapkan oleh peneliti untuk dipelajari dan kemudian ditarik kesimpulan (Azwar, 1997). Karakteristik tertentu ditentukan berdasarkan hasil observasi dan wawancara yang dilakukan oleh peneliti. Subjek penelitian adalah siswa kelas $3 \mathrm{SD}$ 
diKabupaten Kudus, Jawa Tengah. Kelompok kontrol dengan jumlah 12 siswa dan kelompok eksperimen dengan jumlah 21 siswa.

Penelitian ini adalah penelitian eksperimen kuasi. Rancangan yang digunakan dalam penelitian ini adalah the untreated control group design with pretest and posttest (Shadish, Cook, \& Campbell, 2002). Kelompok eksperimen merupakan kelompok yang mendapatkan manipulasi eksperimen, sedangkan kelompok kontrol adalah kelompok yang digunakan untuk menentukan nilai dari variabel

\section{HASIL DAN PEMBAHASAN}

Berdasarkan hasil penelitian diperoleh data responden sebanyak 33 siswa kelas 3 yang dibagi menjadi dua kelompok. Penentuan kelompok berdasarkan hasil penelitian awal dengan menggunakan metode observasi dan wawancara yang menyatakan bahwa subjek penelitian adalah anak tinggal dalam lingkungan sosial ekonomi dan pendidikan yang cenderung tertinggal. Letak daerah yang jauh dari pusat kota menyebabkan akses informasi yang terbatas. Pendidikan anak bukan menjadi prioritas utama, kurang terlihat adanya usaha orang tua untuk memberikan dukungan kepada anak agar dapat mencapai prestasi akademis yang maksimal. Pendidikan bukanlah prioritas utama sebagian besar masyarakat di daerah tersebut, karena taraf pendidikan orang tua yang juga relatif rendah yang menyebabkan pola pikir dimana anak cukup lulus sekolah dasar. Penggunaan bahasa yang masih cenderung menggunakan bahasa daerah, juga menyebabkan proses pembelajaran yang terhambat di sekolah, karena sekolah menggunakan pengantar bahasa Indonesia ketika proses pembelajaran berlangsung. Kecerdasan linguistik dipengaruhi oleh faktor keturunan dan faktor lingkungan tergantung tanpa manipulasi eksperimental dari variabel bebas (Myers \& Hansen, 2002). Pelaksanaan intervensi diawali dengan pretest kepada kelompok eksperimen dan kontrol. Setelah pretest, kelompok eksperimen mendapatkan intervensi pada bulan Maret-Mei 2018. Postest diberikan kepada kelompok eksperimen maupun kelompok kontrol setelah kelompok eksperimen mendapatkan intervensi. Uji non parametrik wilcoxon merupakan uji yang digunakan dalam melakukan analisis data statistik yang ada.

meliputi pola asuh orang tua, perubahan sosial, dan pendidikan anak. Peran orang tua menjadi sangat penting terkait perkembangan kemampuan verbal anak (King, 2009). Beberapa studi sejak beberapa dekade yang lalu, menganalisis keterkaitan pengaruh nutrisi dengan kapasitas intelektual yang menunjukkan ada hubungan positif dan signifikan (Arija et al., 2006). Sejumlah peneliti menunjukkan bukti bahwa ada hubungan antara status sosial ekonomi dengan kemampuan kognitif yang dimulai sejak masak kanak-kanak dan beberapa penelitian menunjukkan bahwa pendidikan orang tua khususnya ibu berhubungan erat dengan pretasi bahasa siswa (Carl, 2014; Cianci, Orsini, Hulbert, \& Pezzuti, 2013; Nikolov \& Csapó, 2018). Beberapa penelitian ini memperlihatkan bahwa lingkungan berpengaruh terhadap kecerdasan, yang menjadikan dasar peneliti untuk mengambil subjek penelitian di daerah tersebut.

Kemampuan verbal terdiri dari enam sub tes, yang kemudian distandardisasi menggunakan norma Wechsler sehingga menghasilkan angka verbal. Angka verbal inilah yang disebut sebagai kemampuan verbal.

Tabel 1. Statistik deksriptif angka verbal

\begin{tabular}{llccc}
\hline Group & & $\mathrm{N}$ & Mean & Standar Deviasi \\
kontrol & pre & 12 & 40,29 & 9,75 \\
& post & 12 & 42,79 & 8,35 \\
\multirow{2}{*}{ eksperimen } & pre & 21 & 38,19 & 11,70 \\
& post & 21 & 43,36 & 9,54 \\
\hline
\end{tabular}


Tabel 1 menunjukkan besarnya rerata dan standar deviasi dari angka verbal. Standar deviasi menunjukkan variasi yang terjadi dalam data yang ada. Ada perbedaan skor standar deviasi kelompok kontrol pada pretes sebesar
9,75 dan posttes sebesar 8,35. Pada kelompok eksperimen juga terdapat perubahan besarnya nilai standar deviasi dengan pretes sebesar 11,70 dan posttes sebesar 9,54.

Tabel 2. Uji Signifikansi Angka Verbal Kelompok Kontrol

\begin{tabular}{ccccc}
\hline kelas & $\mathrm{N}$ & rata-rata ranking & sig (1-tailed) & Kesimpulan \\
Pretes & 12 & 4,80 & 0,1195 & Ho diterima \\
posttes & 12 & 7,71 & & \\
\hline
\end{tabular}

Hasil sig pada tabel 2 sebesar 0,115 dimana Sig $>0,01$. Hal ini menunjukkan bahwa tidak adanya peningkatan yang signifikan pada kemampuan verbal kelompok kontrol setelah dilakukan postes.

Tabel 3. Uji Normalitas angka Verbal Kelompok Eksperimen

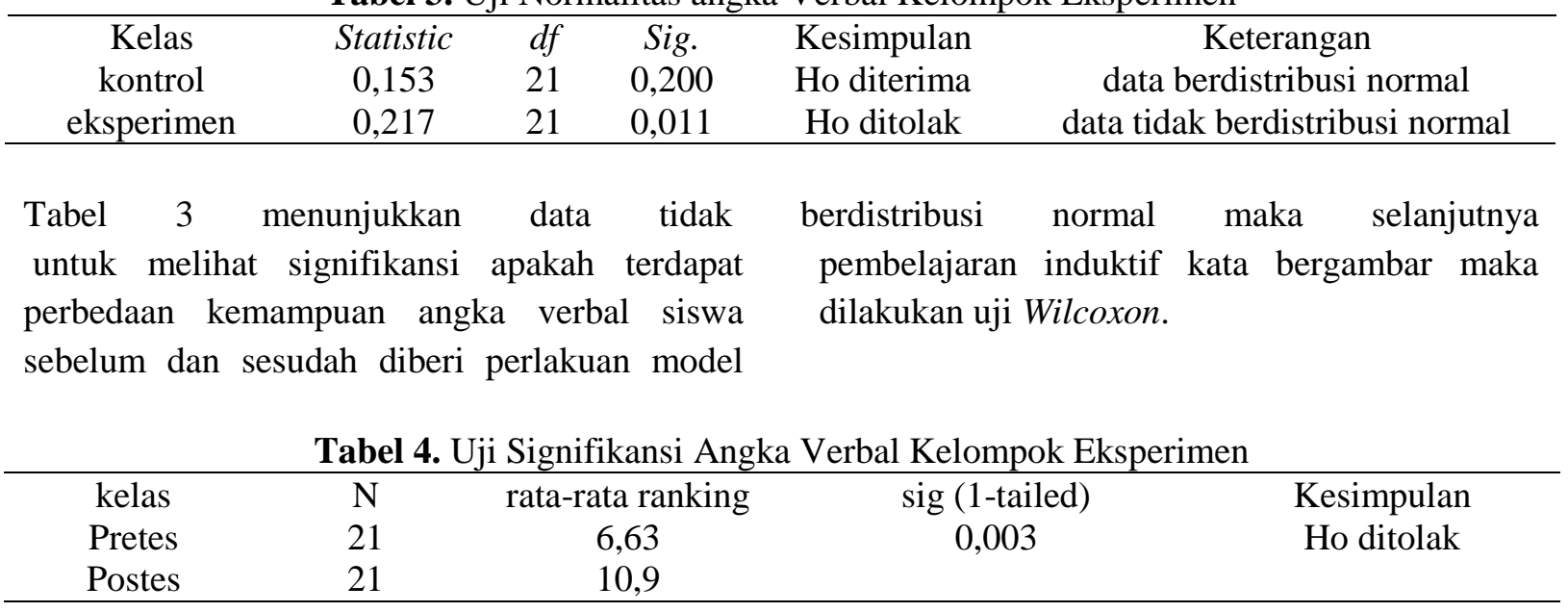

Tabel 4 adalah tabel hasil uji sig sebesar 0,003 dimana $\operatorname{Sig}<0,05$, yang berarti ada peningkatan yang signifikan pada kemampuan verbal kelompok eksperimen setelah dilakukan postes.

Tabel 5. Sumbangan efektif Angka Verbal Kelompok Eksperimen
Kemampuan
Sumbangan efektif
Interpretasi
Angka verbal
0,4958
Sedang 
Tabel 5 memperlihatkan sumbangan efektif model pembelajaran induktif kata bergambar pada kemampuan verbal sebesar 0,49 termasuk pada kategori sedang atau sebesar $27,58 \%$.

Grafik 1. Perbandingan rerata skor angka verbal antara kelompok kontrol dan eksperimen

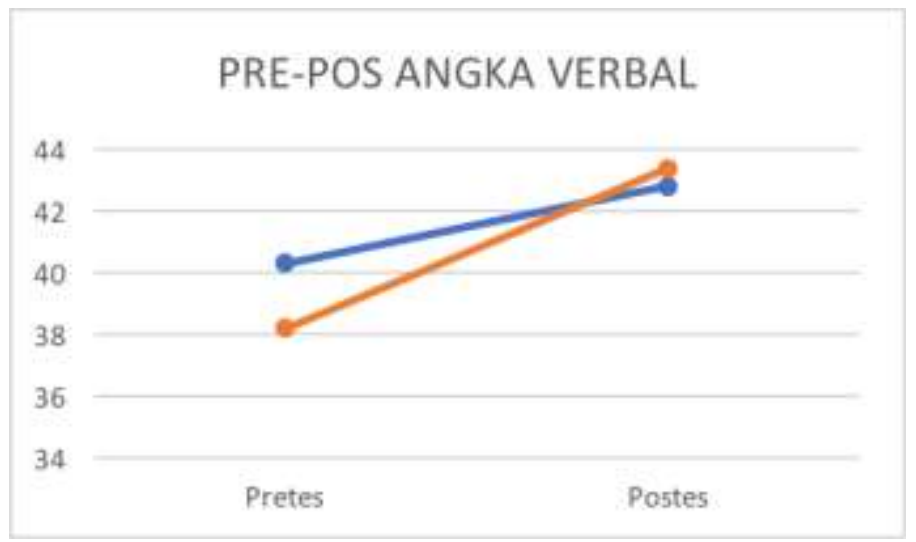

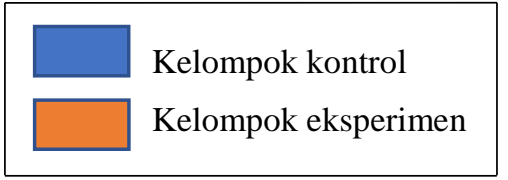

2016;

Patty, 2015; Putra, 2003). Penelitian lain juga mengungkapkan model ini mampu meningkatkan literasi dini anak usia dini secara signifikan. Hal ini memperlihatkan bahwa model induktif kata bergambar merupakan model yang tepat untuk meningkatkan kemampuan bahasa (Bali, Fakhruddin, \& Rifa'i, 2016). Namun menurut pemahaman peneliti, model ini belum secara khusus diujikan menggunakan alat tes WISC.

Penelitian terkait perkembangan inteligensi antara usia 2 tahun dan 16 tahun ternyata juga dipengaruhi oleh status sosial ekonomi. Sangat memungkinkan anak-anak dengan status sosial ekonomi lebih tinggi mempunyai peluang yang lebih besar dalam belajar daripada anak dengan status sosial ekonomi rendah. Perbedaan ketersediaan kesempatan belajar, dukungan dan sumber daya untuk meningkatkan kemampuan kognitif (von Stumm \& Plomin, 2015).

Perspektif neurosains menjelaskan bahwa latihan yang dilakukan berulang-ulang ternyata mampu mengubah area otak yang berhubungan dengan domain latihan secara kognitif atau motorik. Beberapa penelitian menunjukkan bahwa latihan yang dilakukan walaupun dalam waktu yang singkat dapat menyebabkan perubahan di struktur otak di area latihan (Jaušovec \& Pahor, 2017). Tujuan utama upaya peningkatan inteligensi adalah meningkatkan proses dasar yang membentuk perilaku inteligensi dan diharapkan dapat meningkatkan IQ (Jaušovec \& Jaušovec, 2012). Penelitian tentang pengukuran inteligensi anak menemukan bahwa ada peningkatan yang signifikan pada skor IQ anak-anak hasil tes tahun 1984 dan 2006 di China meskipun tidak ditemukan di semua subtes (Liu, Yang, Li, Chen, \& Lynn, 2012).

Perdebatan antara inteligensi dan proses belajar akan selalu muncul, fakta empiris 
penelitian tidak memunculkan definisi yang solid terkait orang dengan inteligensi yang baik akan lebih baik dan cepat memahami pelajaran dibandingkan dengan orang dengan inteligensi yang kurang. Kita tidak tahu apakah seseorang cerdas karena mereka belajar atau mereka belajar lebih baik karena mereka cerdas (Nęcka, Machera, \& Miklas, 1992). Selama beberapa tahun terakhir, sudah banyak metode pelatihan yang berupaya untuk meningkatkan inteligensi dengan subjek orang dewasa namun mendapatkan hasil yang mengecewakan (Hayes, Petrov, \& Sederberg, 2015).

Berbeda dengan usia anak-anak, IQ sering keliru diyakini sebagai sesuatu yang tetap, tidak dapat diubah dan bersifat bawaan. Meskipun memang ada kecenderungan stabilitas IQ yang cukup tinggi sepanjang masa dewasa (Schuerger \& Witt, 1989). Kecerdasan verbal bukanlah sesuatu yang bebas budaya, karena kecerdasan verbal memerlukan kata-kata dan untuk menguasai hal tersebut dan diperlukan proses penguasaan bahasa (Nęcka et al., 1992). Werner dan Kaplan dalam penelitiannya menguji anak-anak usia 8-13 tahun terkait kemampuan mereka untuk memperoleh kata baru, menemukan bahwa (a) kemampuan tersebut meningkat secara bertahap seiring dengan usia, meskipun beberapa proses yang mendasari kemampuan tidak berubah secara bertahap, namun terkadang berubah secara tibatiba; (b) terdapat penurunan awal dan mendadak pada tanda-tanda kekanakan yang berkaitan dengan tugas yang diberikan; (c) proses signifikansi penggunaan kata-kata lebih dominan pada usia 10 dan 11 tahun; dan (d) perilaku berbahasa memperlihatkan perbedaan pengorganisasian bahasa pada usia yang berbeda Sternberg (Sternberg, Powell, \& Kaye, 1982).

\section{SIMPULAN DAN SARAN}

Model pembelajaran induktif kata bergambar pada penelitian ini memberikan pengaruh yang signifikan dalam meningkatkan kemampuan verbal siswa sekolah dasar. Model ini mempunyai sumbangan efektif sebesar 27,58\%. Hasil penelitian ini dapat dijadikan pijakan untuk melakukan penelitian-penelitian selanjutnya khususnya terkait pengembangan dari model pembelajaran induktif kata bergambar.

Penelitian selanjutnya nampaknya perlu melihat sejauh mana efektivitas peningkatan tiap-tiap subtes dalam kemampuan verbal, dan menganalisis faktor-faktor apa saja yang berpengaruh terhadap skor subtes tersebut. Pengembangan model induktif kata bergambar pada penelitian selanjutnya juga diharapkan dapat memperhatikan karakteristik subtes kemampuan verbal.

Salah satu hal yang menjadi limitasi penelitian adalah kuantitas subjek, dimana hal ini dapat dijadikan pertimbangan untuk penelitian-penelitian setelahnya. Gender dalam juga nampaknya menjadi variabel yang menarik untuk diteliti. Apakah kemampuan verbal juga dipengaruhi oleh jenis kelamin.

\section{DAFTAR RUJUKAN}

Andariah, U. (2016). Penerapan model induktif kata bergambar untuk menaikkan keterampilan menulis puisi bebas pada siswa kelas $\mathrm{V}$ serang 4 tahun ajaran 2015/2016, 4.

Arija, V., Esparó, G., Fernández-Ballart, J., Murphy, M. M., Biarnés, E., \& Canals, J. (2006). Nutritional status and performance in test of verbal and non-verbal intelligence in 6 year old children. Intelligence, 34(2), 141-149. https://doi.org/10.1016/j.intell.2005.09.001

Azwar, S. (1997). Realibilitas dan validitas. Yogyakarta: Pustaka Pelajar.

Bali, E. N., Fakhruddin, \& Rifa'i, A. (2016). Pengembangan model pembelajaran induktif kata bergambar untuk pengenalan kemampuan literasi dini AUD. Journal of Primary Education, 5(2), 120-129.

Caemmerer, J. M., Maddocks, D. L. S., Keith, T. Z., \& Reynolds, M. R. (2018). Effects of cognitive abilities on child and youth academic achievement: Evidence from the WISC-V and WIAT-III. Intelligence, 68(November 2016), 6-20. https://doi.org/10.1016/j.intell.2018.02.005

Carl, N. (2014). Verbal intelligence is correlated with socially and economically liberal beliefs. Intelligence, 44(1), 142-148. https://doi.org/10.1016/j.intell.2014.03.005

Cianci, L., Orsini, A., Hulbert, S., \& Pezzuti, L. (2013). The influence of parents' education in the Italian standardization sample of the WISC-III. Learning and Individual Differences, 28, 47-53. https://doi.org/10.1016/j.lindif.2013.09.009 Colman, A. M. (1990). Aspect of intelligence. In The Open University's introduction to psychology, volume 1 (pp. 322-372). 
Deary, I. J., Strand, S., Smith, P., \& Fernandes, C. (2007). Intelligence and educational achievement. Intelligence, 35(1), 13-21. https://doi.org/10.1016/j.intell.2006.02.001

Dodonova, Y. A., \& Dodonov, Y. S. (2012). Processing speed and intelligence as predictors of school achievement: Mediation or unique contribution? Intelligence, $\quad 40(2), \quad 163-171$. https://doi.org/10.1016/j.intell.2012.01.003

Duncan, G. J., Dowsett, C. J., Claessens, A., Magnuson, K., Huston, A. C., Klebanov, P., ... Japel, C. (2007). School Readiness and Later Achievement. Developmental Psychology, 43(6), 1428-1446. https://doi.org/10.1037/00121649.43.6.1428

Gary, G.-M. (2003). Handbook of psychological assessment (4th ed.). New Jersey: John Wiley \& Sons, Inc.

Geary, D. C. (2011). Cognitive predictors of achievement growth in mathematics: A 5year longitudinal study. Developmental Psychology, 47(6), 1539-1552. https://doi.org/10.1037/a0025510

Hayes, T. R., Petrov, A. A., \& Sederberg, P. B. (2015). Do we really become smarter when our fluid-intelligence test scores improve? Intelligence, $48, \quad 1-14$. https://doi.org/10.1016/j.intell.2014.10.005

Herbein, E., Golle, J., Tibus, M., Schiefer, J., Trautwein, U., \& Zettler, I. (2018). Fostering elementary school children's public speaking skills: A randomized controlled trial. Learning and Instruction, 55(October), 158-168. https://doi.org/10.1016/j.learninstruc.2017. 10.008

Huda, M. (2014). Model-model pengajaran dan pembelajaran. Isu-isu metodis dan paradigmatis (5th ed.). Yogyakarta: Pustaka Pelajar.

Hunt, S., Wright, A., \& Simonds, C. (2014). Securing the Future of Communication Education: Advancing an Advocacy and Research Agenda for the 21st Century. Communication Education, 63(4), 449461.

https://doi.org/10.1080/03634523.2014.92 6016

Jaušovec, N., \& Jaušovec, K. (2012). Working memory training: Improving intelligence Changing brain activity. Brain and Cognition, $\quad 79(2)$, 96-106. https://doi.org/10.1016/j.bandc.2012.02.00
7

Jaušovec, N., \& Pahor, A. (2017). Raising Intelligence by Means of Behavioral Training. Increasing Intelligence. https://doi.org/10.1016/b978-0-12-8094075.00003-8

Jensen, A. R. (1998). Human evolution, behaviour, and intelligence. The $g$ factoe: The science of mental ability. Westport: Praeger Publisher. Greenwood Publishing Group.

Joyce, B., Weil, M., \& Calhoun, E. (2011). Models of teaching. Model-model pengajaran. (A. Fawaid \& A. Mirza, Eds.) (2nd ed.). Pustaka Pelajar.

King, L. A. (2009). Psikologi umum (Sebuah pandangan apresiatif) (3rd ed.). Jakarta: Salemba Empat.

Krauss, R. M. (2002). The Psychology of Verbal Communication. Management, 1616116165.

Kuncel, N. R., Hezlett, S. A., \& Ones, D. S. (2004). Academic Performance, Career Potential, Creativity, and Job Performance: Can One Construct Predict Them All? Journal of Personality and Social Psychology, 86(1), 148-161. https://doi.org/10.1037/00223514.86.1.148

Kusminah. (2012). Pengembangan Model Pembelajaran Induktif Kata Bergambar Bermuatan Nilai-Nilai Pendidikan Karakter Aspek Membaca Permulaan Sekolah Dasar. The Journal of Educational Research, 2(May 2012), 37-41. Retrieved from

http://ovidsp.ovid.com/ovidweb.cgi?T=JS $\& C S C=Y \& N E W S=N \& P A G E=$ fulltext $\& D$ $=$ psyc $2 \& A N=1970-02869-001$

Liu, J., Yang, H., Li, L., Chen, T., \& Lynn, R. (2012). An increase of intelligence measured by the WPPSI in China, 19842006. Intelligence, 40(2), 139-144. https://doi.org/10.1016/j.intell.2012.01.008

Luwel, K., Foustana, A., Onghena, P., \& Verschaffel, L. (2013). The role of verbal and performance intelligence in children's strategy selection and execution. Learning and Individual Differences, 24(December 2017),

134-138. https://doi.org/10.1016/j.lindif.2013.01.010

Morreale, S. P., \& Pearson, J. C. (2008). Why communication education is important: The centrality of the discipline in the $21 \mathrm{st}$ century. Communication Education, 57(2), 
224-240. https://doi.org/10.1080/036345207018617 13

Myers, A., \& Hansen, C. H. (2002). Experimental psychology (5th ed.). Pacivic Grove, CA: Wadsworth/Thomson Learning.

Nęcka, E., Machera, M., \& Miklas, E. (1992). Incidental learning, intelligence, and verbal ability. Learning and Instruction, 2(2), 141-153. https://doi.org/10.1016/09594752(92)90028-K

Nikolov, M., \& Csapó, B. (2018). The relationships between 8th graders' L1 and L2 reading skills, inductive reasoning and socio-economic status in early English and German as a foreign language programs. System, 73, 48-57. https://doi.org/10.1016/j.system.2017.11.0 01

Patty, R. (2015). Pengembangan Model Induktif Kata Bergambar Pada Pembelajaran Menulis Permulaan di Kelas II SD, 172179.

Perkins, D. N., \& Grotzer, T. A. (1997). Teaching intelligence. American Psychologist, 10(52), 1125-1133. https://doi.org/http://dx.doi.org/10.1037/00 03-066X.52.10.1125

Piacente, T. (2012). Verbal comprehension of university students. Orientacion $y$ Sociedad, 12.

Putra, N. A. (2003). Penggunaan Media Gambar Seri untuk Meningkatkan Keterampilan Menulis Narasi pada Mata Pelajaran Bahasa Indonesia Siswa Kelas IV SDN Moahino Kabupaten Morowali. Reference, 2(4), 230-242.

Roth, B., Becker, N., Romeyke, S., Schäfer, S., Domnick, F., \& Spinath, F. M. (2015). Intelligence and school grades: A metaanalysis. Intelligence, 53, 118-137. https://doi.org/10.1016/j.intell.2015.09.002

Schneider, R., Lotz, C., \& Sparfeldt, J. R. (2018). Smart, confident, interested: Contributions of intelligence, self-concept, and interest to elementary school achievement. Learning and Individual Differences, 62(October 2017), 23-35. https://doi.org/10.1016/j.lindif.2018.01.003

Schuerger, J. M., \& Witt, A. C. (1989). The temporal stability of individually tested intelligence. Journal of Clinical Psychology, 45(2), 294-302.

Shadish, W. R., Cook, T. D., \& Campbell, D. T.
(2002). Experimental and quasiexperimental designs for generalized causal inference. Boston, New York: Houghton Mifflin Company.

Spinath, B., \& Spinath, F. M. (2005). Development of self-perceived ability in elementary school: The role of parents' perceptions, teacher evaluations, and intelligence. Cognitive Development, 20(2), 190-204. https://doi.org/10.1016/j.cogdev.2005.01.0 01

Sternberg, R. J., Powell, S., \& Kaye, B. (1982). the Nature of Verral Comprehension I L . I 1.

von Stumm, S., \& Plomin, R. (2015). Socioeconomic status and the growth of intelligence from infancy through adolescence. Intelligence, 48, 30-36. https://doi.org/10.1016/j.intell.2014.10.002 Weiss, L. C., Saklofske, D. H., Holdnack, J. A., \& Prifitera, A. (2016). WISC-V: Advances in the assessment of intelligence. In WISC$V$ assessment and interpretation: Scientistpractitioner perspectives. (pp. 3-23). https://doi.org/10.1016/B978-0-12404697-9.00001-7 